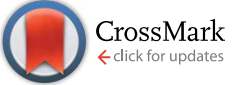

Cite this: RSC Adv., 2017, 7, 7329
Received 20th December 2016 Accepted 16th January 2017

DOI: $10.1039 / c 6 r a 28491 d$

www.rsc.org/advances

\section{Colloid-probe AFM studies of the surface functionality and adsorbed proteins on binary colloidal crystal layers $\uparrow$}

\begin{abstract}
Gurvinder Singh, ${ }^{\star a b}$ Kristen Bremmell, ${ }^{c}$ Hans J. Griesser ${ }^{d}$ and Peter Kingshott ${ }^{\star a e}$
Colloid-probe-AFM has been widely used to measure the forces of interaction between two surfaces such as particles of different size and functionality or a flat surface and a particle in aqueous environments. However, the applicability of colloid-probe AFM to detect different surface chemistries on chemical or protein patterned surfaces has not been demonstrated. We show that the technique can be used to distinguish the regions of different surface chemistries or biomolecules located within a patterned surface in buffer solution. Our previously developed method, based on evaporation induced self-assembly, was used to generate binary colloidal crystal (bCC) layers of different chemical and/or protein patterns. Particles of different size and functionality, with or without adsorbed protein(s), were used to decorate solid supports with the bCCs. The results from the force measurements on the patterned surfaces revealed that the probe experiences both strong or weak repulsive interactions and attractive interactions depending on the net surface charge present on the particles within the bCC patterns. Measurements on bCC patterns where one particle is coated with a single protein demonstrate that the technique can also be used to probe surface diffusion of adsorbed proteins. Therefore, we are able to detect whether a protein remains adsorbed or diffuses to a region on the bCC containing no proteins. Furthermore, the applicability of this technique was extended to detect the presence of two different biomolecules (i.e., lysozyme and bovine serum albumin adsorbed on both the large and small particles) within the protein patterned bCC surface by their different interaction forces. The study demonstrates that colloid-probe AFM can be used to discriminate between the surface properties of binary colloid crystal patterned surfaces where the binary patterns are comprised of particles of either different surface chemistry or particles with different adsorbed proteins.
\end{abstract}

\section{Introduction}

Protein adsorption is an inherently complex process involving protein-protein and protein-surface interactions influencing numerous devices that are used where materials are exposed to biological environments., ${ }^{\mathbf{1} 2}$ In many cases the spontaneous adsorption of proteins on solid materials causes undesired effects. Examples are failure of implantable devices, ${ }^{3,4}$ blocking of membrane pores in bio-separation and purification, ${ }^{5}$ and

\footnotetext{
${ }^{a}$ Interdisciplinary Nanoscience Centre, Faculty of Science, Aarhus University, Ny Munkegade, Aarhus C 8000, Denmark. E-mail: gurvinder.singh@ntnu.no; pkingshott@swin.edu.au

${ }^{b}$ Department of Materials Science and Engineering, Norwegian University of Science and Technology, N-7491 Trondheim, Norway

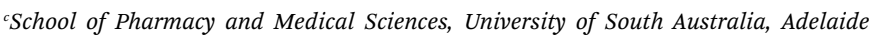
5000, Australia

${ }^{d}$ Future Industries Institute, University of South Australia, Mawson Lakes, SA 5095, Australia

${ }^{e}$ Department of Chemistry and Biotechnology, Faculty of Science, Engineering and Technology, Swinburne University of Technology, Hawthorn, VIC 3122, Australia

$\dagger$ Electronic supplementary information (ESI) available. See DOI: 10.1039/c6ra28491d
}

bacterial colonization of surfaces. ${ }^{6}$ On the other hand, precise control of protein-surface interactions is of crucial importance in cardiovascular implants, tissue engineering, and biosensor and biochip development for medical diagnostics. ${ }^{7-10}$ Over recent decades, there has been considerable progress in the development of novel hybrid biomaterials for biomedical applications through the functionalization of colloidal nanoparticles with proteins/enzymes. ${ }^{\mathbf{1 1 - 1 3}}$ By altering the size, geometry, and surface chemistry of the particle, the surface properties of such materials can be regulated. ${ }^{\mathbf{1 4 , 1 5}}$ For example, curved surfaces are preferred over flat surfaces for protein adsorption allowing ultra-sensitive detection in biosensors. ${ }^{\mathbf{8 , 1 6}}$ Moreover, device performance also strongly depends on the conformation, orientation and spatial arrangement of immobilized proteins. Therefore, precise measurement and understanding of protein-protein and protein-surface interactions at the nanoscale on colloids or within patterned surfaces made of colloidal particles are of critical importance.

A large number of techniques have been developed to examine protein interactions. However, most of them provide information on length scales much larger than the dimension of a single protein and are thus are unable to provide data on 
spatial distribution of biomolecules patterned on a surface in the nanometre size range. ${ }^{17-20}$ However, atomic force microscopy (AFM) has proved to be a versatile and useful tool that provides high-resolution topographical imaging and can study various biological interactions without signal amplification and advanced sample preparation. The detection of molecular interactions at the nanoscale with high sensitivity can be achieved through replacing the sharp cantilever tip with a colloidal particle of well-defined spherical shape with desired surface chemistry and size. ${ }^{21,22}$ Colloid-probe AFM has been widely utilized to probe protein-protein interactions, ${ }^{23-26}$ proteinsurface interactions, ${ }^{27-29}$ interactions between different bare surfaces, ${ }^{30}$ and bacterial adhesion events. ${ }^{31}$ It has also used for studying the morphology and mechanics of cells, and differentiation of various cell types. ${ }^{32,33}$ Recently, we demonstrated that colloid-probe AFM could be used to investigate the interaction between protein coatings on a colloid probe and a hexagonal close-packed monolayer of colloidal particles coated with or without proteins. ${ }^{34}$ The main advantage associated with this approach is that it may provide better insights into how the electrical double-layer of the particle is modified in the presence of other particles in close vicinity. The importance of understanding how proteins interact with colloidal crystals is the discovery that colloidal crystals can elicit different cellular responses such as controlled stem cell differentiation ${ }^{35-37}$ compared to flat surfaces, where the colloidal crystal layer most likely influences how the protein layer is seen by the cells.

In the present study, we examine local variations in the surface chemistry of binary colloidal crystal (bCC) layers prepared from colloidal particles of two different size modified with various proteins. The preparation of the bCC monolayer over centimeter sized areas was reported on water/solid support in our previous works ${ }^{38,39}$ and on air/water interface by Dai et $a{ }^{40}$ Furthermore, we also investigate how the interaction between the protein and surface/protein-protein changes when two different proteins are present in close proximity to each other within a bCC patterned surface. The protein molecules experience different conformational states and surface potentials depending on their adsorption characteristics and the surrounding environment on the surface under physiological conditions. ${ }^{\mathbf{4 1}}$ Thus, by resolving variations in force measurements, it may be possible to detect proteins on the surface without bio-affinity probes. Interactions between different surfaces can be described by DLVO theory, which incorporates contributions from electrostatic and van der Waals forces, and non-DLVO theory including steric, hydration and hydrophobic interactions. ${ }^{\mathbf{4 2 - 4 5}}$ For this study, two model proteins, lysozyme (LZM, isoelectric point: 11.1 , size: $4 \mathrm{~nm} \times 3 \mathrm{~nm} \times 3 \mathrm{~nm}$ ), and bovine serum albumin (BSA, isoelectric point: 4.7 , size: $14 \mathrm{~nm}$ $\times 4 \mathrm{~nm} \times 4 \mathrm{~nm}$ ) were selected since their adsorption behaviour and conformational changes on colloidal particles of different surface chemistries have been well characterized. ${ }^{\mathbf{4 6 4}}$ These proteins have a tendency to adsorb on implant surfaces exposed to the biological media. Polystyrene and silica particles of different size ( $2 \mu \mathrm{m}$ to $110 \mathrm{~nm}$ ) were used because they have different surface functionality and thus provide variable protein adsorption properties.

\section{Experimental}

\subsection{Materials and solvents}

Silica, carboxyl (COOH)-polystyrene (PS), and amine $\left(\mathrm{NH}_{2}\right)$-PS colloid particles in different sizes were purchased from Invitrogen (USA) and Kisker GmbH (Germany) and were stored at $4{ }^{\circ} \mathrm{C}$. Absolute ethanol (Sigma-Aldrich, HLPC grade), toluene (Sigma-Aldrich, $\geq 99.5 \%$ ), and sodium chloride $(\mathrm{NaCl})$ were used as received. Lysozyme (LZM) from chicken egg white (lyophilized powder) and albumin from bovine serum (BSA) (lyophilized powder) were purchased from Sigma-Aldrich. Boron doped silicon wafers with a diameter of $76.2 \mathrm{~mm}$; orientation (100) and a resistivity of $0.0005-0.001 \Omega \mathrm{cm}$ were obtained from Virginia Semiconductors (Virginia, USA).

\subsection{Protein adsorption and assembly formation}

First, colloidal particles were brought to room temperature and sonicated for $30 \mathrm{~min}$ prior to use each time. Colloid particles were dispersed in freshly prepared protein solution $\left(1 \mathrm{mg} \mathrm{mL}^{-1}\right)$ in PBS buffer $(\mathrm{pH}=7.4)$ for $2 \mathrm{~h}$ at room temperature. After protein adsorption, the suspension was washed three times with PBS buffer and once with Milli-Q water $\left(0.5 \mu \mathrm{S} \mathrm{cm} \mathrm{cm}^{-1}\right.$ conductivity) using a centrifuge, and particles were then redispersed in Milli-Q water. Silicon wafers $\left(1 \mathrm{~cm}^{2}\right.$ pieces) were used as a substrate and sonicated for $15 \mathrm{~min}$ each in a solution of ethanol, followed by toluene then ethanol. After drying with a stream of $\mathrm{N}_{2}$ gas, cleaned wafers were UV-ozone treated for $30 \mathrm{~min}$ to remove organic contamination. The detailed experimental procedures for forming binary colloidal crystal assemblies and protein patterned surfaces are well described in our previously work..$^{34,38,39}$ In brief, $1.8 \mu \mathrm{L}$ of $2 \mu \mathrm{m} \mathrm{COOH}-\mathrm{PS}(\phi=5.3$ $\times 10^{-4}, \phi=$ volume fraction) and $0.4 \mu \mathrm{L}$ of $200 \mathrm{~nm} \mathrm{NH}_{2}$-PS $(\phi=$ $9.5 \times 10^{-5}$ ) were mixed in $100 \mu \mathrm{L}$ of Milli-Q water. They were left for $30 \mathrm{~min}$ to allow both particles to become well dispersed. We did not observe any aggregation of particles because both the large and small sized particles possess negative surface potentials as indicated by zeta potential measurements (Table 1). The colloidal suspension was then drop-cast carefully inside the

Table 1 Zeta potential measurements of the colloid particles, with or without adsorbed particles

Particle type

$2 \mu \mathrm{m}$ COOH-PS

$2 \mu \mathrm{m}$ COOH-PS (LZM)

$200 \mathrm{~nm} \mathrm{NH}_{2}$-PS

$200 \mathrm{~nm} \mathrm{NH}_{2}$-PS (LZM)

$200 \mathrm{~nm} \mathrm{NH}_{2}$-PS (BSA)

$110 \mathrm{~nm} \mathrm{NH}_{2}-\mathrm{PS}$

$110 \mathrm{~nm} \mathrm{NH}_{2}$-PS (BSA)

$2 \mu \mathrm{m}$ silica

$2 \mu \mathrm{m}$ silica (LZM)

$200 \mathrm{~nm}$ silica

$200 \mathrm{~nm}$ silica (BSA)

$1 \mu \mathrm{m}$ PS

$1 \mu \mathrm{m}$ PS (BSA)
$1 \mathrm{mM} \mathrm{NaCl}(\mathrm{pH}=7.4)$

$-19.9 \mathrm{mV}$

$-4.7 \mathrm{mV}$

$-18.7 \mathrm{mV}$

$-3.1 \mathrm{mV}$

$-10.4 \mathrm{mV}$

$+6.7 \mathrm{mV}$

$-3.6 \mathrm{mV}$

$-10.5 \mathrm{mV}$

$1.4 \mathrm{mV}$

$-11.2 \mathrm{mV}$

$-7.3 \mathrm{mV}$

$-28.9 \mathrm{mV}$

$-13.9 \mathrm{mV}$ 
rubber ring fixed on the substrate and left for the solvent to evaporate in a vacuum desiccator at room temperature. After drying the solution, a monolayer of bCC was obtained. Protein patterned bCC surfaces were obtained by mixing protein coated particles and the same procedure mentioned above was used to generate the bCC assemblies.

\subsection{Force curve measurements}

A Nanoscope III AFM (Digital Instrument, USA) was used to collect force curves in a commercial fluid cell. Commercially available V-shaped cantilevers with attached $1 \mu \mathrm{m}$ plain PS particle (Novascan Technologies, Ames, IA, USA) were cleaned with ethanol and water before the measurement each time. The spring constant of the cantilevers was determined by the method of thermal tuning and found to be $0.032 \pm 0.013 \mathrm{~N}$ $\mathrm{m}^{-1} \cdot{ }^{48}$ A dried monolayer of binary colloidal crystals deposited on the silicon wafer was placed in the AFM, and an aqueous solution of $1 \mathrm{mM} \mathrm{NaCl}$ was added to the fluid cell through the syringe. A conditioning period of $15 \mathrm{~min}$ was used to reach equilibrium each time before starting force measurements. First, the sample was scanned over $10 \mu \mathrm{m}^{2}$ area by liquid contact mode AFM. The magnified areas of $\sim 2.5 \mu \mathrm{m}^{2}$ and $\sim 1.0$ $\mu \mathrm{m}^{2}$ around single large particles $(2 \mu \mathrm{m})$ and several small particles $(200 \mathrm{~nm})$, respectively were also scanned. The force curves were collected assuming the probe centered over large particles with a precision $\sim 100 \mathrm{~nm}$. An excel spreadsheet was used to convert the raw force curve data into normalized force $\left(F / 2 \pi R_{\mathrm{f}}\right)$ versus apparent separation $(d, \mathrm{~nm})$, where $R_{\mathrm{f}}$ is the effective radius. Colloid probes were modified with BSA by a protocol reported in our earlier work. ${ }^{34} \mathrm{~A}$ Zetasizer Nano series (Malvern Instrument, UK) was used to measure the zeta potential of the colloidal particles before and after protein adsorption. We have assumed the surface potential of the colloid-probe attached to cantilever as being equivalent to the 1 $\mu \mathrm{m}$ PS colloid particles in a solution of the same chemistry for the analysis of force curves.

\section{Results and discussion}

\subsection{Binary colloid crystal monolayer preparation}

A schematic diagram illustrating the formation of a bCC monolayer from particles of two different sizes with or without a protein coating is shown in Fig. 1a. The detailed mechanistic understanding of bCC layer formation is described in our previous work. $^{38,39}$ In brief, when a colloidal suspension was spread over the area encircled by the rubber ring, spatial confinement coupled with the evaporation of the solvent facilitates the selfassembly of the bCC layer onto the substrate, mainly driven by capillary, convective, and electrostatic forces. This evaporationinduced method permits utilization of a wide range of particle sizes from $\mu \mathrm{m}$ to $\mathrm{nm}$, and provides control over the binary crystal layer morphology by changing the size ratio of the particles and their concentration. This method enable the formation of bCC layer over large area $\left(\mathrm{cm}^{2}\right.$ scale) with $90 \%$ uniformity. ${ }^{49}$

The AFM height image displayed the topography of the selfassembled binary protein pattern made from a mixture of LZMcoated $2 \mu \mathrm{m}$ COOH-PS and BSA-coated $200 \mathrm{~nm} \mathrm{NH} \mathrm{N}_{2}$-PS, scanned by a plain PS colloid-probe of diameter $1 \mu \mathrm{m}$ (Fig. 1b). Crosssectional analysis showed the centre-to-centre distance between LZM-coated particles to be $2 \mu \mathrm{m}$, and the height differences between the $2 \mu \mathrm{m}$ PS and $200 \mathrm{~nm}$ PS particles to be $\sim 100 \mathrm{~nm}$ (Fig. 1b). If we assume uniform adsorption of protein over the particles, LZM-coated colloids are surrounded by colloids bearing $\mathrm{BSA}$, in a well-arranged hexagonal arranged fashion.

a)

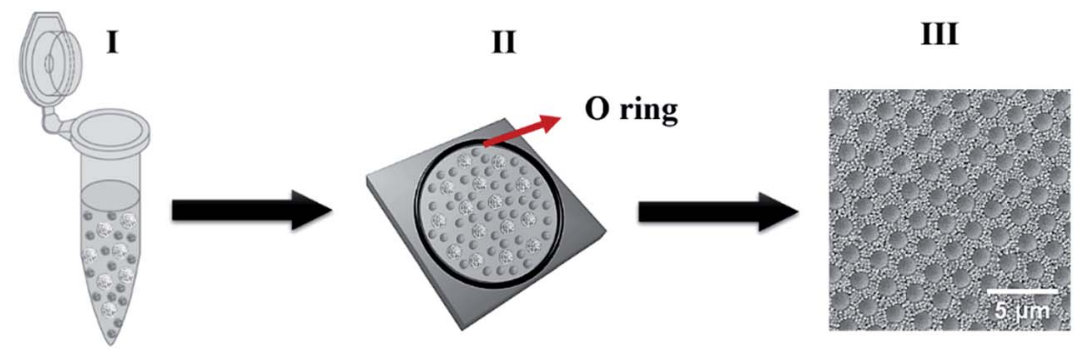

b)

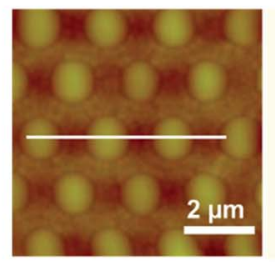

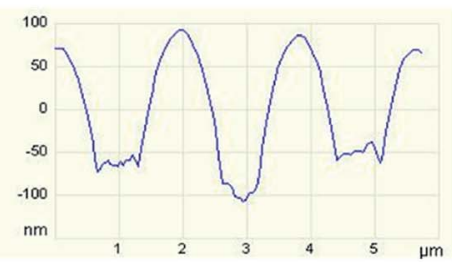

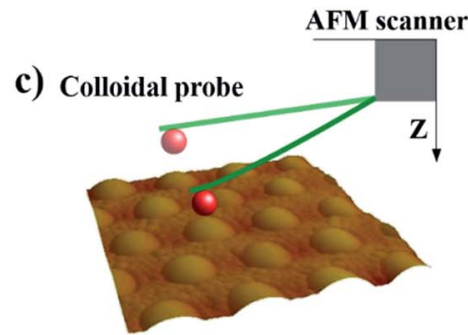

Fig. 1 (a) Schematic diagram illustrating the formation of the binary colloidal crystal (bCC) layers; (I) colloidal suspension of two different sized particles with or without protein coatings, (II) spreading of the colloidal suspension onto a defined area on a hydrophilic substrate encircled by

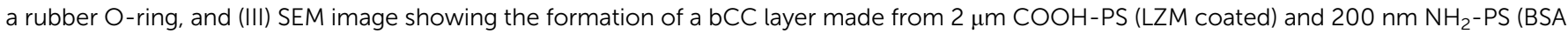
coated). (b) Liquid contact mode AFM images of bCCs, and cross-section analysis indicating center to center distances between two large particles $(2 \mu \mathrm{m})$. (c) 3D topography and force measurement on large and small particles by selecting a magnified area of $\sim 2.5 \mu \mathrm{m}^{2}$ and $\sim 1 \mu \mathrm{m}^{2}$, respectively. 


\subsection{Force measurements on binary colloid crystals}

For force curve measurements, the magnified regions around the large and small particles was selected, and the colloid-probe was placed centrally (as close as possible) over the large particles or areas where small particles made up the bCC. First, representative approach force curves were collected on a bCC monolayer made from particles without protein coatings, i.e., 2 $\mu \mathrm{m}$ COOH-PS and $200 \mathrm{~nm} \mathrm{NH}$-PS in $1 \mathrm{mM} \mathrm{NaCl}(\mathrm{pH}=7.4$ ) solution (Fig. 2). Zeta ( $\zeta)$ potential measurements revealed on these particles had negative surface potentials in $1 \mathrm{mM} \mathrm{NaCl}$ $(\mathrm{pH}=7.4)$ (Table 1). In an aqueous medium, the charging of the surfaces can originate in two ways, either by the dissociation of surface groups (e.g., the dissociation of protons from carboxylic or hydroxyl groups) or by the adsorption of counterions onto the particle surface. The surface potential present at the interface causes an electrostatic field which decays exponentially with increasing distance from the surface. It is surprising that $200 \mathrm{~nm}$ particles having $\mathrm{NH}_{2}$ as surface groups were found to
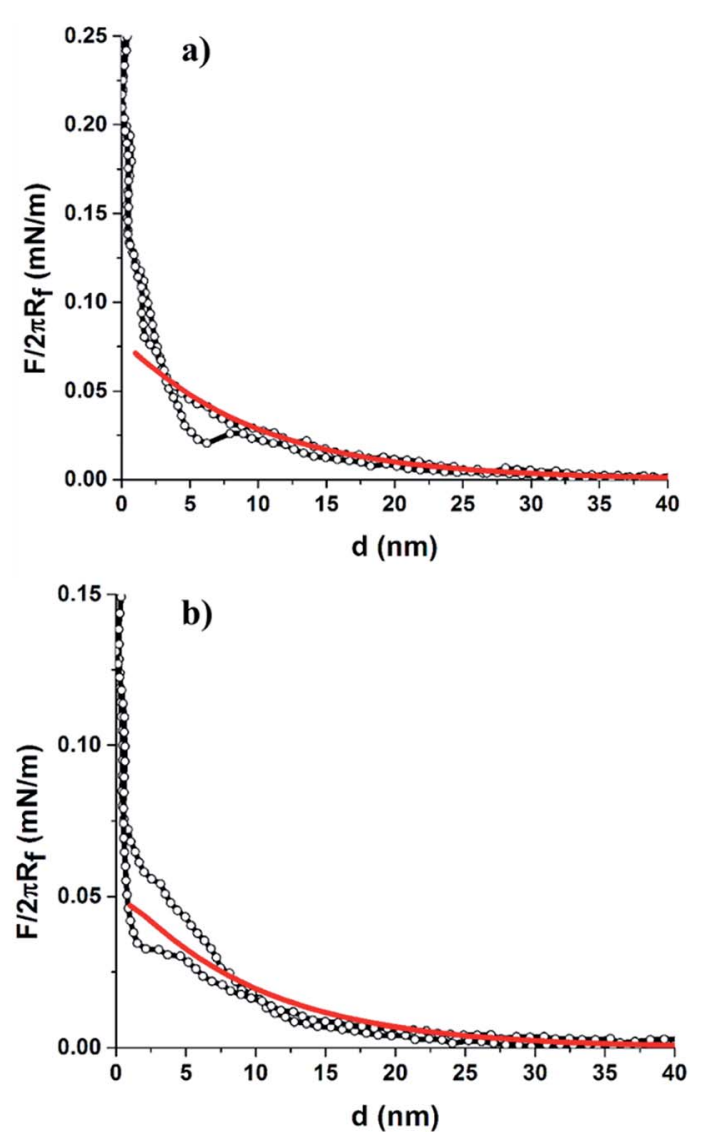

Fig. 2 Normalized force $\left(F / 2 \pi R_{f}\right)$ versus apparent separation (d) approach curves for the interaction between a PS colloid-probe and a bCC layer comprising $2 \mu \mathrm{m} \mathrm{COOH}-\mathrm{PS}$ and $200 \mathrm{~nm} \mathrm{NH}$-PS. The approach force curves were collected in an aqueous solution of $1 \mathrm{mM}$ $\mathrm{NaCl}(\mathrm{pH}=7.4)$. (a) On the $2 \mu \mathrm{m} \mathrm{COOH}$-PS region; (b) on the $200 \mathrm{~nm}$ $\mathrm{NH}_{2}-\mathrm{PS}$ region of the bCC. The solid red line represents the theoretical fit using surface potentials $\varphi_{\text {probe-PS }}=-28.9 \mathrm{mV}, \varphi_{2 \mu \mathrm{m}-\mathrm{Ps}}=-19.9 \mathrm{mV}$ and $\varphi_{200 \mathrm{~nm} \text {-PS }}=-18.7 \mathrm{mV}$. The Debye length $\left(\kappa^{-1}\right)$ measured from the fit corresponded to the ionic strength of solution $(9.6 \mathrm{~nm}$ for $1 \mathrm{~mm}$ $\mathrm{NaCl}$. bear a negative $\zeta$-potential $(-18.7 \mathrm{mV})$. It may due to either low graft density of amine groups over the surface bearing carboxyl functional groups or the presence of residual anionic surfactants on the particles. ${ }^{50}$ The detailed surface characterization of $200 \mathrm{~nm} \mathrm{NH} \mathrm{NH}_{2}$-PS was shown in our previous work. ${ }^{38}$

At large separation, a repulsive interaction was dominant. Since the surface potential of $2 \mu \mathrm{m} \mathrm{COOH}-\mathrm{PS}\left(\varphi_{2} \mu \mathrm{m}-\mathrm{PS}=-19.9\right.$ $\mathrm{mV})$ is slightly higher than the $200 \mathrm{~nm} \mathrm{NH} \mathrm{NH}_{2}$-PS $\left(\varphi_{200 \mathrm{~nm}-\mathrm{Ps}}=\right.$ $-18.7 \mathrm{mV})$, thus, a colloid-probe $\left(\varphi_{1} \mu \mathrm{m}\right.$-probe $\left.=-28.9 \mathrm{mV}\right)$ recognized a slightly stronger repulsive interaction against the 2 $\mu \mathrm{m}$ COOH-PS particles in the bCC (Fig. 2a and b). To verify the origin of this interaction, DLVO theory was used to fit the measured force curve profiles for both the systems (i.e., colloidprobe/COOH-PS and colloid-probe/ $\mathrm{NH}_{2}$-PS). According to DLVO theory, the total interaction force between two spherical particles can be written as the sum of electrical double interactions (EDL) and van der Waals interactions (vdW): $:^{\mathbf{3 4 , 4 3 , 4 4}}$

$$
\frac{F}{2 \pi R_{\mathrm{f}}}=2 \pi \varepsilon \varepsilon_{\mathrm{o}} \kappa \gamma_{1} \gamma_{2}\left(\frac{4 k_{\mathrm{B}} T}{q}\right)^{2} \mathrm{e}^{-\kappa d}+\frac{A}{6 d^{2}}
$$

where $F / 2 \pi R_{\mathrm{f}}$ is the normalized force interaction between the particles, $R_{\mathrm{f}}$ is effective radius $\left(R_{\mathrm{f}}=R_{1} R_{2} / R_{1}+R_{2}, R_{1}\right.$ and $R_{2}$ are the radii of particle and probe), $\varepsilon_{\mathrm{o}}$ is the permittivity of free space, $\varepsilon$ the permittivity of aqueous medium, $\kappa^{-1}$ is the Debye length measuring the thickness of EDL, $\gamma$ is the normalized surface potential $\left(\gamma=\tanh \left(q \varphi / 4 k_{\mathrm{B}} T\right)\right), k_{\mathrm{B}}$ is Boltzmann's constant, $T$ is the absolute temperature, $q$ is the ionic charge, $d$ is the separation, and $A$ is the Hamaker constant. In the right hand side of eqn (1), the first term is the EDL, and the second term is the vdW interaction.

The DLVO theory fitted well with our experimentally measured approach force curve profiles and suggested the repulsive EDL interaction between the particles by the overlapping of the diffuse layer. ${ }^{34,51}$ Since the colloid probe is difficult to place centrally over individual $200 \mathrm{~nm}$ particles, we have assumed that the probe interacts with more than one small $200 \mathrm{~nm}$ particle. In this case, the interaction between the particle and a flat surface was considered as the probe $/ \mathrm{NH}_{2}-\mathrm{PS}$ system. Differences in the surface chemistries/properties were detected on the bCC layer made from $2 \mu \mathrm{m} \mathrm{COOH}-\mathrm{PS}$ and $110 \mathrm{~nm} \mathrm{NH}$-PS by the colloid-probe. The $2 \mu \mathrm{m}$ and $110 \mathrm{~nm}$ particles have different zeta potentials, of opposite sign $\left(\varphi_{2} \mu \mathrm{m}\right.$-PS $=-19.9 \mathrm{mV}$ and $\varphi_{110} \mathrm{~nm}-\mathrm{Ps}=+6.7 \mathrm{mV}$ ). The approach force curve profiles between the PS probe and the $2 \mu \mathrm{m}$ COOH-PS particle were similar to that shown in Fig. 2a. The force curves acquired on regions bearing $110 \mathrm{~nm}$ particles were shown to have a different behavior (Fig. 3). In this case, a weak attractive EDL interaction was seen with the onset of a weak attractive van der Waals's interaction below $10 \mathrm{~nm}$ separation. The experimental results for the probe/110 $\mathrm{nm} \mathrm{NH}_{2}$-PS system showed a deviation from DLVO theory when they were fitted to the theory using the measured surface potential of the $110 \mathrm{~nm}$ particles by the zetasizer $\left(\varphi_{110 \mathrm{~nm}-\mathrm{Ps}}=+6.7 \mathrm{mV}\right)$. This indicated a weaker attractive interaction than that predicted by DLVO theory. The best fit was obtained correspond to the surface potential of $\varphi_{110 \mathrm{~nm}-\mathrm{PS}}=+1.5 \mathrm{mV}$ (Fig. 3, solid red line). A similar 


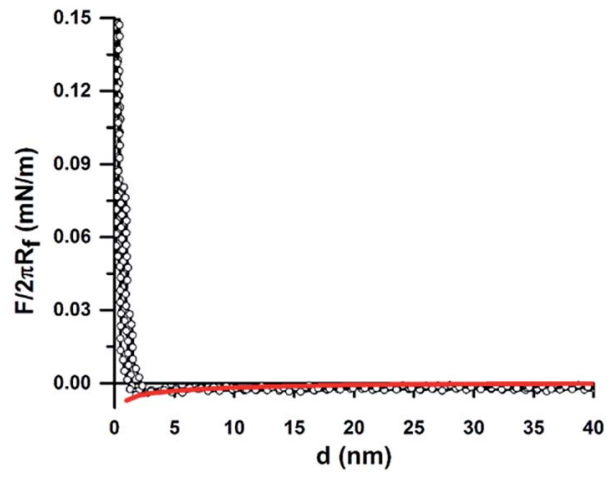

Fig. 3 Normalized force $\left(F / 2 \pi R_{f}\right)$ versus apparent separation (d) approach curves for the interaction between a PS colloid-probe and $110 \mathrm{~nm} \mathrm{NH}$-PS particles within the bCC layer comprising $2 \mu \mathrm{m}$

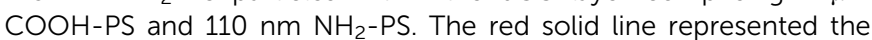
theory fit using measured zeta potentials $\varphi_{1} \mu \mathrm{m}$-probe $=-28.9 \mathrm{mV}$ and $\varphi_{110 \mathrm{~nm}-\mathrm{PS}}=1.5 \mathrm{mV}$

disagreement between the theory and experimental results was observed between sulfated PS particles in the presence of positively charged polyelectrolyte because of heterogenous adsorption..$^{52,53}$ We also suspect two possible reasons. First, charge regulation of particles may occur when they are deposited on a hydrophilic negatively charged surface, thus creating a lower charge than predicted by $\zeta$-potential measurements. Second, the adsorption of some carbonaceous contamination from the atmosphere on the dried crystal layer before starting the measurement can also lead to a decrease in the surface potential. Furthermore, we compared these results with our previous study in the single colloidal crystal (sCC) layers. No difference in the interaction force was found when the measurement was performed either between the probe and bCC layer or separately between the probe and a colloidal crystal layer made of one particle. ${ }^{34}$ We also observed similar behavior in the approach force curves obtained between the probe and a bCC made from $2 \mu \mathrm{m}$ silica and $200 \mathrm{~nm}$ silica particles (Fig. S1†). The force curve fitting with surface potentials $\varphi_{2 \mu \mathrm{m} \text {-silica }}=-10.5 \mathrm{mV}$ and $\varphi_{200 \mathrm{~nm} \text {-silica }}=-11.2 \mathrm{mV}$ showed a close agreement with DLVO theory at large separation.

Overall, these results indicate that colloid-probe AFM can differentiate between different surface regions on binary colloidal crystal patterned surfaces in real-time and under aqueous conditions. The detailed mechanism to detect different surface chemistries by the colloid-probe is described in our previous work. ${ }^{34}$

In brief, when a negatively charged colloid-probe approaches the surface, the strength of the electrostatic interaction (either repulsive or attractive) can be changed by the modification of surface with molecules of different functionality, e.g., amine, carboxylic, etc., as well as $\mathrm{pH}$ and ionic strength of the medium.

\subsection{Force measurements of protein-coated binary colloid crystals}

Next, we performed measurements on the bCC pattern with a single protein pattern, which was formed by assembling LZM

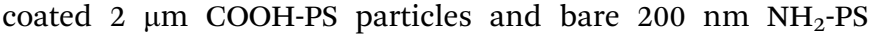
particles onto the hydrophilic silicon substrate. Force curve profiles were collected on LZM-coated $2 \mu \mathrm{m}$ COOH-PS and $200 \mathrm{~nm} \mathrm{NH} \mathrm{N}_{2}$-PS regions at various points across the patterned surface. The colloid probe experienced a weaker EDL repulsive interaction against LZM-coated $2 \mu \mathrm{m}$ COOH-PS particles (Fig. 4a), with an onset of $\sim 20 \mathrm{~nm}$ separation that is less than the unmodified $2 \mu \mathrm{m}$ COOH-PS in a bCC $(\sim 35-40 \mathrm{~nm})$. LZM is assumed to have an overall positive charge in PBS buffer $(\mathrm{pH}=$ 7.4), and its adsorption on the negatively charged $2 \mu \mathrm{m} \mathrm{COOH}-$ PS regulates the overall surface charge of the particle. Our $\zeta-$ potential measurements showed a decrease in the surface potential of $2 \mu \mathrm{m}$ COOH-PS from $-19.9 \mathrm{mV}$ to $-4.7 \mathrm{mV}$ after LZM adsorption (Table 1). This result is consistent with our previous study of force measurements on LZM coated monocomponent colloidal crystal of particles by a colloid-probe
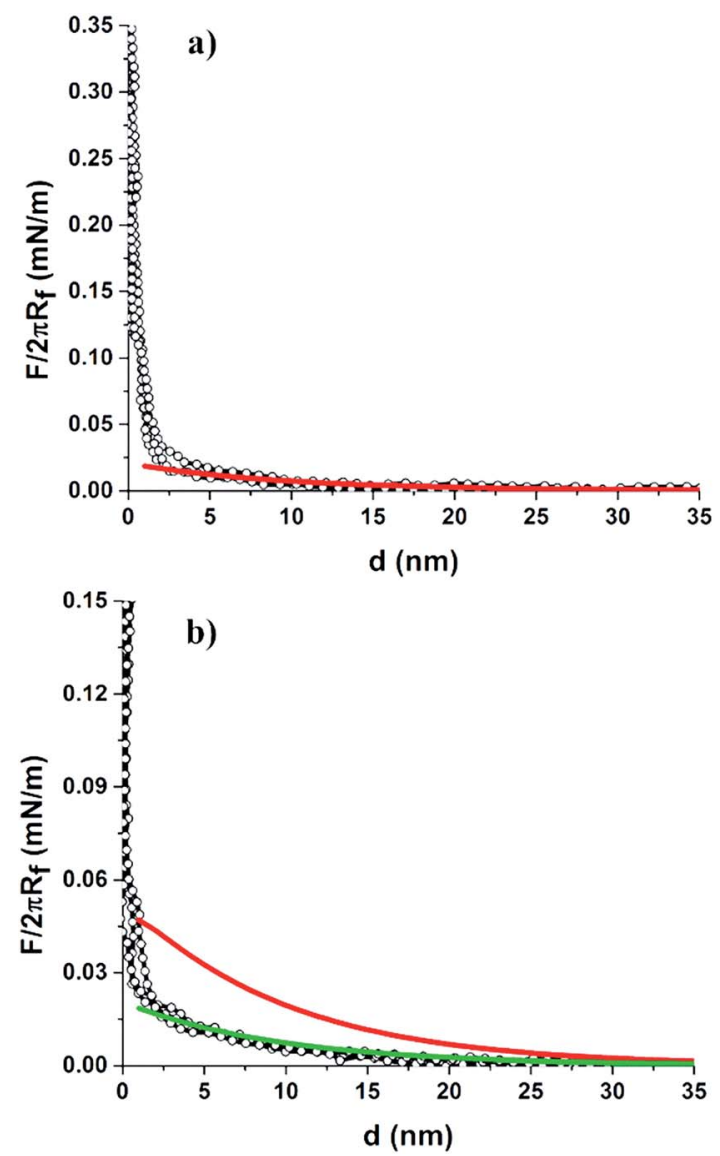

Fig. 4 Normalized force $\left(F / 2 \pi R_{f}\right)$ versus apparent separation (d) approach curves for the interaction between a PS colloid-probe and a bCC layer made from LZM coated $2 \mu \mathrm{m} \mathrm{COOH}$-PS and unmodified $200 \mathrm{~nm} \mathrm{NH} \mathrm{N}_{2}$-PS. The approach force curves were collected in an aqueous solution of $1 \mathrm{mM} \mathrm{NaCl}(\mathrm{pH}=7.4)$. (a) On the LZM coated $2 \mu \mathrm{m}$ $\mathrm{COOH}-\mathrm{PS}$ region of the $\mathrm{bCC}$, and the solid red line represents the theoretical fit using surface potentials $\varphi_{\text {probe-PS }}=-28.9 \mathrm{mV}$, and $\varphi_{2 \mu \mathrm{m} \text {-PS (LZM) }}=-4.7 \mathrm{mV}$; (b) on the $200 \mathrm{~nm} \mathrm{NH}_{2}$-PS region of the bCC. The solid red line is the theoretical fit using surface potential $\varphi_{\text {probe-PS }}$ $=-28.9 \mathrm{mV}$ and $\varphi_{200 \mathrm{~nm}-\mathrm{PS}}=-18.7 \mathrm{mV}$. The best fit was achieved by using the surface potential of $\varphi_{200 \mathrm{~nm}-\mathrm{PS}}=-5.0 \mathrm{mV}$, displayed by solid green line. 
AFM. ${ }^{34}$ Furthermore, DLVO theory fitted well with our experimentally measured force curves at large separation.

The colloid-probe also experienced a weak repulsive interaction against the unmodified $200 \mathrm{~nm} \mathrm{NH}_{2}$-PS region of the bCC (Fig. 4b), which onsets at a separation of $\sim 25-20 \mathrm{~nm}$ in comparison to the force curve profiles shown in Fig. $2 \mathrm{~b}(\sim 35-40$ $\mathrm{nm})$. Moreover, the force curve did not fit very well to DLVO theory using the surface potential of $\varphi_{200} \mathrm{~nm}$-Ps $=-18.7 \mathrm{mV}$, which was confirmed by $\zeta$-potential measurements (Table 1). The best fit was obtained with a less negative surface potential for $200 \mathrm{~nm}$ PS particle (i.e., $\varphi_{200 \mathrm{~nm}-\mathrm{PS}}=-5.0 \mathrm{mV}$ ). Here, we speculate that the $200 \mathrm{~nm} \mathrm{NH}$-PS particles did not remain unmodified after bCC formation. There is the potential that they had accumulated a (partial) layer of LZM, which might have occurred by transferal off the LZM-coated $2 \mu \mathrm{m}$ COOH-PS particles during the bCC formation. This led to the regulation of surface charge on the $200 \mathrm{~nm}$ particles. To verify this, the $200 \mathrm{~nm} \mathrm{NH}_{2}$-PS particles were coated with LZM under the same conditions as the $2 \mu \mathrm{m} \mathrm{COOH}-\mathrm{PS}$, and $\zeta$-potential measurement of LZM modified $200 \mathrm{~nm}$ particles showed a less negative surface potential (i.e., $-3.1 \mathrm{mV}$ ) (Table 1). Our results suggest that the variation in the surface chemistry within a BCC layer can be detected by the colloid-probe AFM technique because the probe experiences different magnitudes of either repulsive or attractive electrostatic forces depending on the polarity and size of the surface charge. These results are in the agreement with our previous investigation. ${ }^{34}$ The range of these interactions and the discrimination between binary colloid crystal regions can be tuned by varying the surface potential. These force curves can also probe whether proteins remain adsorbed on the original particle or diffuse to neighboring regions (i.e., desorb and readsorb on the other type of particle).

We also investigated the interactions of the colloid-probe with the binary protein patterned surface. This was prepared by assembling the mixed colloidal suspension of LZM coated 2 $\mu \mathrm{m}$ COOH-PS particles with BSA-coated $200 \mathrm{~nm} \mathrm{NH}_{2}$-PS (or BSAcoated $110 \mathrm{~nm} \mathrm{NH}_{2}$-PS) on the hydrophilic silicon substrate. ${ }^{38}$ Colloid-probe measurements showed differences in the interaction force curves obtained from the two regions, i.e., from LZM coated $2 \mu \mathrm{m} \mathrm{COOH}-\mathrm{PS}$ and BSA-coated $200 \mathrm{~nm} \mathrm{NH}_{2}$-PS (or BSA-coated $110 \mathrm{~nm} \mathrm{NH}_{2}$-PS) as illustrated in Fig. 5. LZM and BSA are assumed to a carry an overall positive and negative charge, respectively, at $\mathrm{pH}=7.4$. Thus, their adsorption onto the particle surface triggers a surface charge regulation, and the resultant net surface charge on the particle depends on the surface chemistry of the particle and the ionic strength of the solution in which the measurements take place. The $\zeta$-potential measurements confirm the decrease in surface potential after protein adsorption in $1 \mathrm{mM} \mathrm{NaCl}\left(\varphi_{2} \mu \mathrm{m}-\mathrm{Ps}(\mathrm{LZM})=-4.7 \mathrm{mV}\right.$, $\varphi_{200 \mathrm{~nm}-\mathrm{PS}(\mathrm{BSA})}=-10.5 \mathrm{mV}$, and $\left.\varphi_{110 \mathrm{~nm}-\mathrm{PS}(\mathrm{BSA})}=-0.8 \mathrm{mV}\right) . \mathrm{In}$ this case, we did not notice any significant difference in the force curve profile of LZM coated $2 \mu \mathrm{m} \mathrm{COOH}-\mathrm{PS}$ in comparison to the profile shown in Fig. 4a (i.e., with a similar onset of a repulsive interaction at a separation of approximately $20 \mathrm{~nm}$ ). Close examination of the force curve profile for BSA-coated particles revealed a stronger repulsive interaction with onsets at a large separation of $\sim 35-40 \mathrm{~nm}$ compared to LZM coated 2
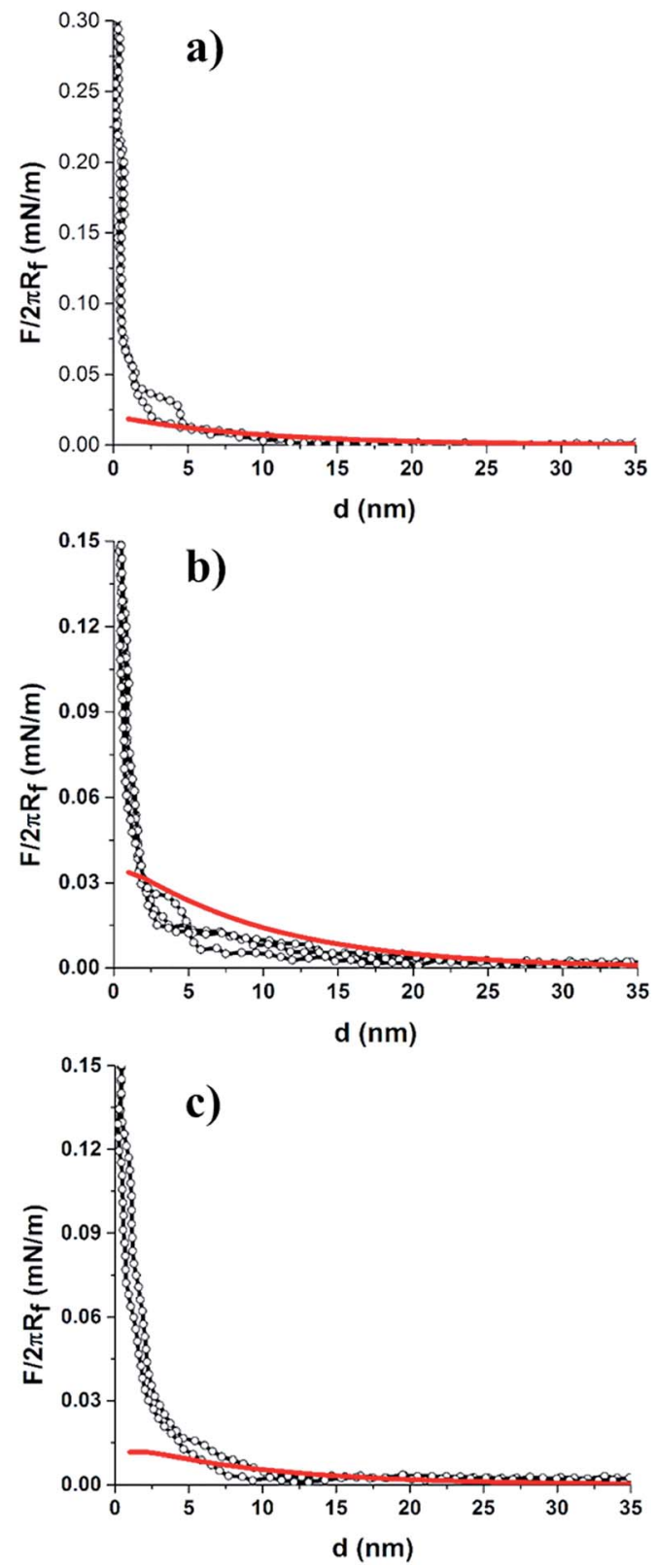

Fig. 5 Normalized force $\left(F / 2 \pi R_{f}\right)$ versus apparent separation (d) approach curves for the interaction between a PS colloid-probe and a bCC layer made from LZM coated $2 \mu \mathrm{m} \mathrm{COOH-PS}$ and BSA-coated $200 \mathrm{~nm} \mathrm{NH} \mathrm{H}_{2}$-PS. The approach force curves were collected in an aqueous solution of $1 \mathrm{mM} \mathrm{NaCl}(\mathrm{pH}=7.4)$. (a) On the LZM-coated 2 $\mu \mathrm{m} \mathrm{COOH}-\mathrm{PS}$, and the solid red line represents the theoretical fit using surface potentials $\varphi_{\text {probe-PS }}=-28.9 \mathrm{mV}$, and $\varphi_{2 \mu \mathrm{m} \text {-PS (LZM) }}=-4.7 \mathrm{mV}$; (b) on the $200 \mathrm{~nm} \mathrm{NH}_{2}$-PS bCC region. The solid red line represents the theoretical fit using surface potential $\varphi_{\text {probe-PS }}=-28.9 \mathrm{mV}$ and

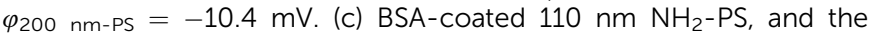
theoretical fit by solid red line using $\varphi_{\text {probe-PS }}=-28.9 \mathrm{mV}$ and $\varphi_{110 \mathrm{~nm}-\mathrm{PS}}=-3.6 \mathrm{mV}$.

$\mu \mathrm{m}$ particles $(\sim 20 \mathrm{~nm})$. This was due to a more negative surface potential of BSA-coated $200 \mathrm{~nm}$ particles as indicated by $\zeta$ potential measurements (Table 1 ). The results also showed good fitting of the force curve profiles of both the LZM coated 2 $\mu \mathrm{m}$, and BSA-coated $200 \mathrm{~nm}$ PS particles using DLVO theory. 
The interaction force curve profile was also measured between the colloid-probe and BSA-coated $110 \mathrm{~nm} \mathrm{NH} \mathrm{NH}_{2}$-PS region on the binary protein patterned surface containing LZMcoated $2 \mu \mathrm{m}$ COOH-PS and BSA-coated $110 \mathrm{~nm} \mathrm{NH}_{2}$-PS particles as displayed in Fig. 5c. In this case, the colloid-probe experienced a weak repulsive interaction which onsets at a separation of $\sim 15-20 \mathrm{~nm}$ rather different to the interaction measured on BSA-coated $200 \mathrm{~nm}$ PS particles in a bCC pattern $(\sim 35-40 \mathrm{~nm})$. The weak repulsive interaction of the probe against BSA coated $110 \mathrm{~nm}$ particles can be explained by considering the surface potential of the particles after the adsorption of BSA. $\zeta$-Potential measurements revealed the low surface potential of BSA-coated $110 \mathrm{~nm}$ particles $\left(\varphi_{110 \mathrm{~nm}-\mathrm{PS} \text { (BSA) }}=-3.6 \mathrm{mV}\right)$ compared to BSA coated $200 \mathrm{~nm}$ particles $\left(\varphi_{200 \mathrm{~nm}-\mathrm{PS}(\mathrm{BSA})}=-10.5 \mathrm{mV}\right)$ (Table 1). This could be a result of a different surface concentration of BSA on both particles, which is feasible if they had a difference in $\mathrm{NH}_{2}$ functional group density. In fact, the $\zeta$-potential values of the unmodified particles are markedly different (Table 1) supporting this assumption. Furthermore, the difference in the surface chemistry of these particles was also confirmed by X-ray photoelectron spectroscopy analysis as investigated in our previous work. $^{38}$ It should be noted that the electrostatic repulsive interactions between the colloid-probe and the $2 \mu \mathrm{m}$ COOH-PS (LZM) were found to be similar to that shown in Fig. 5a. We also performed force measurements on LZM and BSA adsorbed to $2 \mu \mathrm{m}$ and $200 \mathrm{~nm}$ silica particles, respectively. The force curve profile for LZM coated $2 \mu \mathrm{m}$ silica within a bCC indicated the suppression of repulsive interactions in comparison to LZM coated $2 \mu \mathrm{m}$ COOH-PS particles (Fig. S2a $\dagger$ ). On the other hand, a repulsive interaction was seen between the probe and BSA-coated $200 \mathrm{~nm}$ silica particles (onset at the separation of $\sim 20 \mathrm{~nm}$ ), which is also weaker than BSA coated $200 \mathrm{~nm} \mathrm{NH}_{2}$ PS ( 35-40 nm). The suppressed and weaker repulsive interactions for the LZM and BSA-coated silica particles are due to the low surface potential of the silica particles after the LZM and BSA adsorption, which is confirmed by $\zeta$-potential measurements (Table 1). Therefore, the colloid-probe AFM technique also provides discrimination between the different adsorbed proteins comprising the binary protein array, depending on their surface charge.

The study was extended to probe protein-protein interactions between proteins adsorbed on the bCC layer and proteins coated on the colloidal probe. To investigate such interactions, the $1 \mu \mathrm{m}$ PS probe was coated with BSA molecules, and representative force curves were collected when LZM-coated $2 \mu \mathrm{m}$ COOH-PS and BSA-coated $110 \mathrm{~nm} \mathrm{NH}_{2}$-PS particles were approached by the BSA coated colloid-probe (Fig. 6). At large separation, the BSA-coated colloid-probe experienced a rather strong electrostatic repulsive interaction against LZM-coated 2 $\mu \mathrm{m}$ particles compared to BSA-coated $110 \mathrm{~nm}$ particles. This may be rationalised from the $\zeta$-potentials with the measured values of $\varphi_{1 \mu \mathrm{m} \text {-probe (BSA) }}=-13.9 \mathrm{mV}, \varphi_{2} \mu \mathrm{m}$-PS (LZM) $=-4.7 \mathrm{mV}$, and $\varphi_{110} \mathrm{~nm}-\mathrm{Ps}(\mathrm{BSA})=-3.6 \mathrm{mV}$. Comparing the results shown in Fig. 5 and 6, the BSA coated colloid-probe experienced a strong repulsive interaction against LZM coated $2 \mu \mathrm{m}$ COOH-PS (onset at the separation of $\sim 25-30 \mathrm{~nm}$ ), and BSA-coated $110 \mathrm{~nm} \mathrm{NH}_{2}$ PS (onset at $\sim 20-25 \mathrm{~nm}$ ) compared to forces measured with the
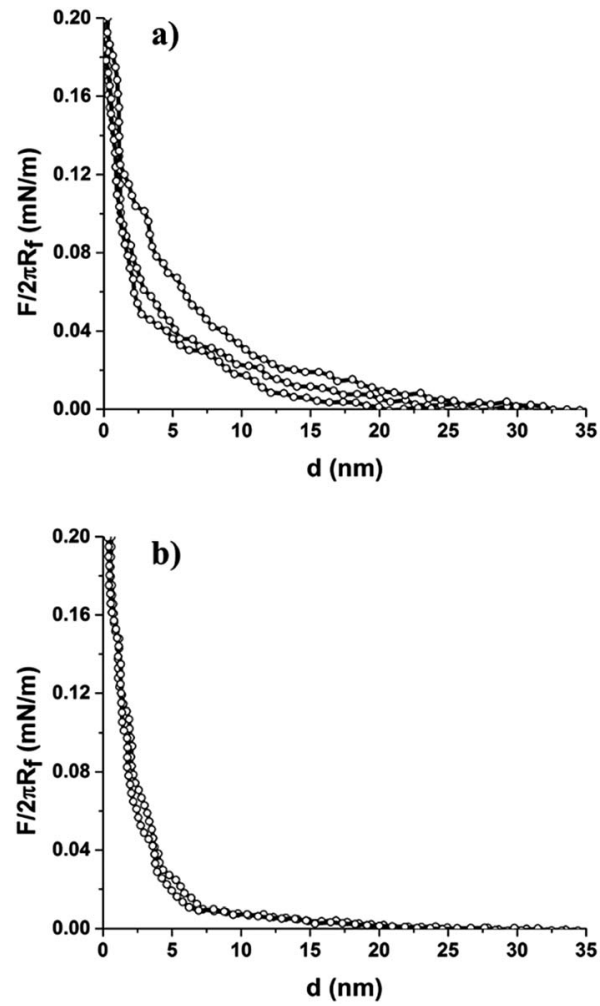

Fig. 6 Normalized force $\left(F / 2 \pi R_{f}\right)$ versus apparent separation (d) approach curves for the interactions between a BSA-coated PS colloid-probe and binary protein patterned surface made from LZMcoated $2 \mu \mathrm{m} \mathrm{COOH}$-PS and BSA-coated $110 \mathrm{~nm} \mathrm{NH}_{2}$-PS in $1 \mathrm{mM} \mathrm{NaCl}$ $(\mathrm{pH}=7.4)$. (a) On the LZM-coated $2 \mu \mathrm{m} \mathrm{COOH}$-PS region, and (b) on the BSA-coated $110 \mathrm{~nm} \mathrm{NH}_{2}$-PS region of the bCC.

bare colloid-probe. Assuming a dominant role of surface potentials (i.e., neglecting conformational changes within the time frame of the experiment), interactions must be smaller when both surfaces are coated with proteins. Interpretation of such protein-protein interactions, however, cannot be explained solely by DLVO theory incorporating electrostatic interactions and van der Waals attractions, as it requires the inclusion of the role of other, non-DLVO forces. The conformation of the adsorbed protein layer depends on the solution ionic strength, and it may adopt an expanded conformation in a low ionic strength solution because of increased repulsion among the charged protein molecules on the surface in $1 \mathrm{mM}$ NaCl. ${ }^{54-56}$ However, the extent of conformational changes in the adsorbed layer of proteins on the particles is difficult to access by looking for differences in the force curves. The possibility of protein denaturation after adsorption is less likely based on our previous investigation demonstrating the binding of antibodies to the LZM coated particles within a binary protein patterned surface. ${ }^{38}$ Moreover, TOF-SIMS study of filgrastim (a globular protein) showed that drying of adsorbed filgrastim under high vacuum did not cause any signification denaturation of the protein. ${ }^{57}$ Finally, we did not observe any aggregation of particles when LZM and BSA-coated particles were mixed in the aqueous solution before self-assembly. This indicated the repulsive interaction between the particles coated with different 
proteins. Moreover, the results obtained with BSA-coated colloid-probe are in agreement with our previous study showing the strong repulsive interaction between the adsorbed proteins on the particles. ${ }^{34}$

\section{Conclusions}

We have demonstrated the applicability of the colloid-probe AFM technique to discriminate between different surface chemistries on the binary colloidal crystal patterned surfaces made from particles of different size and particles coated with different proteins. As the AFM colloid-probe approaches the surface of the bCC layer, different force-distance interaction curves were recorded on two different regions (large and small sized particles) on the patterned surface. A bare colloid-probe experienced a strong repulsive interaction to weak repulsive interaction or attractive interaction depending on the net charge on the particles coated with or without proteins. Our study showed that this technique can also be used to probe whether proteins remain adsorbed on the original particle or diffuse to neighboring regions (i.e., desorb and re-adsorb on the other type of particle) as demonstrated on a single protein patterned surface made from LZM coated $2 \mu \mathrm{m} \mathrm{COOH}-\mathrm{PS}$ and $200 \mathrm{~nm} \mathrm{NH}_{2}$-PS. We also showed that the two different proteins adsorbed onto particles of different size and self-assembled into a bCC layer could be distinguished by differences in interaction forces. DLVO theory was used to fit the experimentally collected force curve profiles using the surface potentials as a fitting parameter. The surface potential was measured by $\zeta$-potential measurements. The experimental force curves were found to satisfactorily fit DLVO theory if charge regulation is included. When a protein coated probe was used, the binary protein pattern can still be observed qualitatively via different interaction forces; however, the inclusion of non-DLVO forces would be required for quantitative studies. Given the generality of this approach for surface or protein sensing, colloid-probe-AFM can be used to examine bCCs or other surface patterns containing different surface functional groups (e.g. carboxyl or amine), or with adsorbed proteins, under different ionic strengths and pHs. The applicability of this method is very broad and reliable since it depends on the interplay of fundamental interactions between the surfaces with operational capability under physiological conditions. Thus, this technique for probing chemically contrasting surfaces can further be expanded to a wide variety of applications in biology and materials science.

\section{Acknowledgements}

This work was funded by a Danish Research Council Internationalisation PhD Stipend and the Ian Wark Research Institute, University of South Australia.

\section{Notes and references}

1 A. J. Oakley and M. C. J. Wilce, Clin. Exp. Pharmacol. Physiol., 2000, 27, 145-151.
2 W. Z. Zhang and R. C. Augusteyn, Curr. Eye Res., 1994, 13, 225-230.

3 T. J. Webster, L. S. Schadler, R. W. Siegel and R. Bizios, Tissue Eng., 2001, 7, 291-301.

4 A. G. Shard and P. E. Tomlins, Regener. Med., 2006, 1, 789800.

5 J. H. Hanemaaijer, T. Robbertsen, T. Vandenboomgaard and J. W. Gunnink, J. Membr. Sci., 1989, 40, 199-217.

6 J. D. Bryers, Colloids Surf., B, 1994, 2, 9-23.

7 T. G. Drummond, M. G. Hill and J. K. Barton, Nat. Biotechnol., 2003, 21, 1192-1199.

8 J. M. Nam, C. S. Thaxton and C. A. Mirkin, Science, 2003, 301, 1884-1886.

9 D. F. Williams, J. Mater. Sci., 1987, 22, 3421-3445.

10 H. Zhu and M. Snyder, Curr. Opin. Chem. Biol., 2003, 7, 5563.

11 K. T. Nguyen and Y. L. Zhao, Acc. Chem. Res., 2015, 48, 30163025.

12 A. Weidner, C. Grafe, M. von der Luhe, H. Remmer, J. H. Clement, D. Eberbeck, F. Ludwig, R. Muller, F. H. Schacher and S. Dutz, Nanoscale Res. Lett., 2015, 10, 1-11.

13 R. Baron, B. Willner and I. Willner, Chem. Commun., 2007, 323-332, DOI: 10.1039/b610721b.

14 A. Hung, S. Mwenifumbo, M. Mager, J. J. Kuna, F. Stellacci, I. Yarovsky and M. M. Stevens, J. Am. Chem. Soc., 2011, 133, 1438-1450.

15 P. Roach, D. Farrar and C. C. Perry, J. Am. Chem. Soc., 2006, 128, 3939-3945.

16 S. Song, Y. Qin, Y. He, Q. Huang, C. Fan and H. Y. Chen, Chem. Soc. Rev., 2010, 39, 4234-4243.

17 J. Marra and J. Israelachvili, Biochemistry, 1985, 24, 46084618.

18 M. M. Elmahdy, C. Gutsche and F. Kremer, J. Phys. Chem. C, 2010, 114, 19452-19458.

19 D. Velegol, J. L. Anderson and S. Garoff, Langmuir, 1996, 12, 4103-4110.

20 C. E. McNamee, M. Kappl, H. J. Butt, J. Ally, H. Shigenobu, Y. Iwafuji, K. Higashitani and K. Graf, Soft Matter, 2011, 7, 10182-10192.

21 H. J. Butt, Biophys. J., 1992, 63, 578-582.

22 W. A. Ducker, T. J. Senden and R. M. Pashley, Nature, 1991, 353, 239-241.

23 L. Meagher and H. J. Griesser, Colloids Surf., B, 2002, 23, 125-140.

24 J. J. Valle-Delgado, J. A. Molina-Bolivar, F. Galisteo-Gonzalez, M. J. Galvez-Ruiz, A. Feiler and M. W. Rutland, Langmuir, 2006, 22, 5108-5114.

25 S. O. Vansteenkiste, S. I. Corneillie, E. H. Schacht, X. Chen, M. C. Davies, M. Moens and L. Van Vaeck, Langmuir, 2000, 16, 3330-3336.

26 L. C. Xu, V. Vadillo-Rodriguez and B. E. Logan, Langmuir, 2005, 21, 7491-7500.

27 K. E. Bremmell, P. Kingshott, Z. Ademovic, B. WintherJensen and H. J. Griesser, Langmuir, 2006, 22, 313-318.

28 S. Kidoaki, Y. Nakayama and T. Matsuda, Langmuir, 2001, 17, 1080-1087. 
29 G. V. Lubarsky, M. M. Browne, S. A. Mitchell, M. R. Davidson and R. H. Bradley, Colloids Surf., B, 2005, 44, 56-63.

30 I. Larson, C. J. Drummond, D. Y. C. Chan and F. Grieser, Langmuir, 1997, 13, 2109-2112.

$31 \mathrm{M}$. N. Chandraprabha, P. Somasundaran and K. A. Natarajan, Colloids Surf., B, 2010, 75, 310-318.

32 K. E. Bremmell, A. Evans and C. A. Prestidge, Colloids Surf., $B, 2006,50,43-48$.

33 S. Iyer, R. M. Gaikwad, V. Subba-Rao, C. D. Woodworth and I. Sokolov, Nat. Nanotechnol., 2009, 4, 389-393.

34 G. Singh, K. E. Bremmell, H. J. Griesser and P. Kingshott, Soft Matter, 2015, 11, 3188-3197.

35 P.-Y. Wang, S. S.-C. Hung, H. Thissen, P. Kingshott and R. C.-B. Wong, Sci. Rep., 2016, 6, 36845.

36 P.-Y. Wang, H. Thissen and P. Kingshott, ACS Appl. Mater. Interfaces, 2016, 8, 4477-4488.

37 P.-Y. Wang, H. Pingle, P. Koegler, H. Thissen and P. Kingshott, J. Mater. Chem. B, 2015, 3, 2545-2552.

38 G. Singh, S. Pillai, A. Arpanaei and P. Kingshott, Adv. Mater., 2011, 23, 1519-1523.

39 G. Singh, S. Pillai, A. Arpanaei and P. Kingshott, Soft Matter, 2011, 7, 3290-3294.

40 Z. Dai, Y. Li, G. Duan, L. Jia and W. Cai, ACS Nano, 2012, 6, 6706-6716.

41 T. J. Su, J. R. Lu, R. K. Thomas, Z. F. Cui and J. Penfold, Langmuir, 1998, 14, 438-445.

42 E. J. W. Verwey, J. T. G. Overbeek and J. T. G. Overbeek, Theory of the stability of lyophobic colloids, Courier Corporation, 1999.
43 H. Ohshima, J. Colloid Interface Sci., 1995, 171, 525-527.

44 D. Mccormack, S. L. Carnie and D. Y. C. Chan, J. Colloid Interface Sci., 1995, 169, 177-196.

$45 \mathrm{~J}$. N. Israelachvili, Intermolecular and surface forces: revised third edition, Academic press, 2011.

46 W. Norde and C. E. Giacomelli, Macromol. Symp., 1999, 145, 125-136.

47 W. Norde and J. P. Favier, Colloids Surf., 1992, 64, 87-93.

48 J. P. Cleveland, S. Manne, D. Bocek and P. K. Hansma, Rev. Sci. Instrum., 1993, 64, 403-405.

49 P. Koegler, M. Dunn, P.-Y. Wang, H. Thissen and P. Kingshott, Crystals, 2016, 6, 84-95.

50 A. Musyanovych and H. J. P. Adler, Langmuir, 2005, 21, 22092217.

51 M. Borkovec, I. Szilagyi, I. Popa, M. Finessi, P. Sinha, P. Maroni and G. Papastavrou, Adv. Colloid Interface Sci., 2012, 179, 85-98.

52 Y. Nakamura, M. Okachi, A. Toyotama, T. Okuzono and J. Yamanaka, Langmuir, 2015, 31, 13303-13311.

53 M. Finessi, P. Sinha, I. Szilagyi, I. Popa, P. Maroni and M. Borkovec, J. Phys. Chem. B, 2011, 115, 9098-9105.

54 H. L. Zhang, K. E. Bremmell and R. S. Smart, J. Biomed. Mater. Res., Part A, 2005, 74, 59-68.

$55 \mathrm{X}$. Wu and G. Narsimhan, Langmuir, 2008, 24, 4989-4998.

56 O. G. Hampe, Eur. J. Biochem., 1972, 31, 32-37.

57 I. M. Kempson, P. Chang, K. Bremmell and C. A. Prestidge, Langmuir, 2013, 29, 15573-15578. 